\title{
Correction to: Context-Sensitive Cognitive and Educational Testing
}

\author{
Robert J. Sternberg ${ }^{1,2}$ \\ Published online: 23 August 2018 \\ (C) Springer Science+Business Media, LLC, part of Springer Nature 2018
}

\section{Correction to: Educ Psychol Rev (2018) 30(3): 857-884 https://doi.org/10.1007/s10648-017-9428-0}

The following parts of "Context-Sensitive Cognitive and Educational Testing" by R. J. Sternberg draw heavily from Sternberg, R. J. (2014), The development of adaptive competence: Why cultural psychology is necessary and not just nice. Developmental Review, 34, 208-224, including the following sections:

- Study in Rural Kenya

- A Study Among Yupi'k Children

- A Further Study Among Yup'ik Eskimo Children

- Dynamic Assessment

The online version of the original article can be found at https://doi.org/10.1007/s10648-017-9428-0

\section{Robert J. Sternberg}

robert.sternberg@cornell.edu

1 Cornell University, B44 MVR, Ithaca, NY, USA

2 Department of Human Development, College of Human Ecology, Ithaca, NY 14853, USA 